\title{
Tobacco taxation, illegal cigarette supply and geography: findings from the ITC Uruguay Surveys
}

\author{
Dardo Curti, ${ }^{1}$ Ce Shang, ${ }^{2}$ Frank J Chaloupka, ${ }^{2,3,4}$ Geoffrey T Fong ${ }^{5,6}$
}

${ }^{1}$ Research Department, Centro de Investigación para la Epidemia del Tabaquismo-CIET, Montevideo, Uruguay

${ }^{2}$ Health Policy Center, Institute for Health Research and Policy, University of Illinois at Chicago, Chicago, Illinois, USA

${ }^{3}$ Department of Economics, University of Illinois at Chicago, Chicago, Illinois, USA

${ }^{4}$ WHO Collaborating Centre on the Economics of Tobacco and

Tobacco Control, USA ${ }^{5}$ Department of Psychology, University of Waterloo, Waterloo Ontario, Canada

${ }^{6}$ Ontario Institute for Cancer Research, Toronto, Ontario, Canada

Correspondence to Professor Dardo Curti, Research Department, Centro de Investigación para la Epidemia del TabaquismoCIET, Montevideo, UY 11100, Uruguay; dardocurti@gmail.com

Received 21 December 2017 Revised 28 August 2018 Accepted 1 September 2018 Published Online First 5 October 2018

\section{ABSTRACT}

Background In Uruguay, real tobacco taxes increased significantly during 2005-2010 and 2014-2017 and decreased during 2010-2014. The effects of these tax changes on illegal and legal cigarette usage differed significantly when we compared cities in the middle and south of the country with cities on the border.

Objective This paper analyses whether supply side factors such as geographical location, distribution networks and the effectiveness of tobacco control play a significant role in sales and use of illegal cigarettes when tobacco taxes change, particularly given the price gap between legal and lower-priced illegal cigarettes. Methods Using the International Tobacco Control Evaluation Project Uruguay Survey data $(2008,2010$, 2012 and 2014), choices among illegal, legal and roll-your-own cigarettes are estimated as a function of smokers' geographical location, an indicator of illegal cigarette supply, and controlling for socioeconomic and demographic variables. Smoking behaviours in Montevideo, Durazno and Maldonado were compared with those in two border cities, Salto and Rivera, where illegal cigarette prevalence may differ.

Findings An increase in taxes on manufactured legal and roll-your-own cigarettes increased the odds that smokers in cities near the borders and women switched down to illegal cigarettes. City geographical location, controls effectiveness and distribution networks may play a significant role in accessibility of illegal cigarettes. To improve the effectiveness of increased taxes and prices in reducing smoking, policy-makers may consider specific policies intended to reduce access to illegal cigarettes, such as ratification and effective implementation of the Protocol to Eliminate Illicit Trade in Tobacco Products of WHO.

\section{INTRODUCTION}

Since Uruguay ratified the Framework Convention on Tobacco Control (FCTC) of WHO in 2004 (table 1), which is the first global health treaty of WHO, taxes on tobacco products (in constant pesos) increased between 2004 and 2010, followed by a decrease in taxes between 2010 and 2014, and a second round of increases from 2014 to 2017 (figure 1 and table 1). These changes in the taxation of tobacco products led to changes in the relative and absolute prices of tobacco products, which in turn impacted consumers' choices of tobacco products given their inverse relationship.

Moreover, due to high specific excise taxes on cigarettes, there is limited price variability between cigarette brands in Uruguay. ${ }^{23}$ Hence, a more feasible way of tax avoidance is to switch down to cheaper illegal or roll-your-own (RYO) cigarettes. ${ }^{4}$ According to the Global Adult Tobacco Survey conducted in 2009 , approximately $32.4 \%$ of cigarette smokers in
Uruguay smoke RYO cigarettes ${ }^{i}$ which is a specific characteristics of the tobacco market in Uruguay compared with just a 7.7\% level of RYO use in Argentina. ${ }^{i i} \mathrm{RYO}$ is used mostly by men, among those who smoke RYO, just between $20 \%$ and $25 \%$ are women. While Uruguay has raised its excise taxes on manufactured cigarettes multiple times since 2004, the excise taxes on RYO tobacco have remained substantially low until the tax rate on RYO tobacco increased from $50 \%$ to $70 \%$ in $2010 .{ }^{4}$

In border cities, there is a potential pattern of tax avoidance, from either cross-border shopping in countries where cigarettes are sold at a lower price, or purchasing illegal cigarettes (ie, tax evasion) smuggled from other countries. In border cities of Uruguay, the latter is the main source of border trade in cigarettes. In 2015 a 20-cigarette pack of the top selling cigarette brand costs $\$ 3.35$ in Uruguay, whereas in neighbour countries Argentina, Paraguay and Brazil, the top selling brands only cost $\$ 1.77, \$ 0.35$ and $\$ 2.54$, respectively.iii

A common argument by the tobacco industry is that tobacco tax increases raise the price of cigarettes, thus mechanically increasing smuggling. ${ }^{5}$ In order to generate economic incentives for illegal trade, a price gap is necessary to increase illegal cigarette trade and use ${ }^{6-8}$ However, to generate a supply of illegal cigarettes requires wholesale distribution channels, legal and illegal retailers willing to sell illegal cigarettes, and smokers who purchase them. Moreover, it is required that smugglers avoid border controls and other controls carried out along the distribution chain.

In contrast with other regions in the world, in the Mercosur ${ }^{\text {iv }}$ region the illegal trade of cigarettes involves low-priced little known brands. ${ }^{5}$ In Uruguay, the illegal cigarette segment has been dominated by Paraguayan brands which are introduced by smugglers using different access points along the border with Argentina and Brazil, and reach Uruguayan cities via a network of distributors. ${ }^{5}$ The International Tobacco Control Evaluation Project (ITC) Uruguay Survey data show that more than $90 \%$ of foreign cigarette brands come from Paraguay, and one brand (known as 51) has a market share of the illegal cigarette

${ }^{\mathrm{i}}$ http://www.cdc.gov/tobacco/global/

${ }^{i i}$ http://www.who.int/tobacco/surveillance/survey/gats/ arg_country_report_2012.pdf

iii http://www.who.int/tobacco/global_report/2015/ appendix $2 . p d f$ ?ua $=1$

${ }^{\mathrm{iv}}$ The Mercosur region is consists Argentina, Bolivia, Brazil, Uruguay, Paraguay and Venezuela. Chile, Colombia, Ecuador, Guyana, Peru and Surinam are the associated states. 


\begin{tabular}{|c|c|}
\hline February 2004 & Framework Convention on Tobacco Control ratification. \\
\hline \multirow[t]{3}{*}{ March 2005} & Tobacco tax increase. \\
\hline & Ban on misleading descriptors. \\
\hline & $\begin{array}{l}\text { Ban on advertisements, promotion and sponsorship at sports } \\
\text { and public events. }\end{array}$ \\
\hline \multirow[t]{2}{*}{ March 2006} & $\begin{array}{l}100 \% \text { smoke-free areas. Implemented for all indoor public } \\
\text { environments, workplaces (including bars and restaurants) and } \\
\text { public transportation. }\end{array}$ \\
\hline & 'A million thanks' media national campaign. \\
\hline April 2006 & Round 1 pictorial warnings. Images at $50 \%$. \\
\hline February 2008 & Round 2 pictorial warnings. Images at $50 \%$. \\
\hline \multirow[t]{2}{*}{ March 2008} & Mandatory promotion of cessation and treatment. \\
\hline & $\begin{array}{l}\text { Tobacco dependence treatment integrated into the National } \\
\text { Healthcare System. }\end{array}$ \\
\hline April 2008 & Tobacco advertising and promotion ban. \\
\hline February 2009 & Round 3 pictorial warnings. Images at $50 \%$. \\
\hline June 2009 & Tobacco tax increase. \\
\hline December 2009 & Round 4 pictorial warnings. Images at $80 \%$. \\
\hline February 2010 & Ban on multiple presentation per brand (brand's variant). \\
\hline March 2010 & Tobacco tax increase. \\
\hline January 2012 & Round 5 pictorial warnings. Images at $80 \%$. \\
\hline May 2012 & $\begin{array}{l}\text { Educational media campaign to increase awareness and } \\
\text { promote cessation. }\end{array}$ \\
\hline June 2014 & $\begin{array}{l}\text { Ratification of the Protocol to Eliminate the Illicit Trade in } \\
\text { Tobacco Products. }\end{array}$ \\
\hline July 2014 & Ban of promotion in the point of sale. \\
\hline June 2015 & Tobacco tax increase. \\
\hline January 2016 & Tobacco tax increase. \\
\hline January 2017 & Tobacco tax increase. \\
\hline April 2017 & Plain packaging bill presented to parliament. \\
\hline January 2018 & Tobacco tax increase. \\
\hline August 2018 & Plain packaging decree-law. \\
\hline
\end{tabular}

market measured by foreign brands of $41.0 \%, 59.2 \%, 75.8 \%$ and 62.1\% in 2008, 2010, 2012 and 2014, respectively. ${ }^{v}$

Some cities in Uruguay are in close proximity to Argentina and Brazil, including Rivera that borders with Brazil and Salto that borders Argentina. Another city that could be prone to the sale of illegal cigarettes is the capital city Montevideo, where 65\% of the Uruguayan population reside in its metropolitan area and may become the target of cigarette tax evasion. Furthermore, a notably active trade port in the city is involved in much of the foreign commerce between Uruguay and neighbouring countries which allows potential exposure to illegal cigarettes.

Regionally, the figures of illegal brands consumption in Montevideo remain low and steady between $10 \%$ and $15 \%$ which could be explained by institutional strengths and specific policies aimed at fighting against illegal trade of tobacco products. Controls along the borders and along routes into Montevideo, and in the city itself by groups of inspectors of the ministry of health, could have helped to deter retailers from selling illegal cigarettes.

This study aims to analyse the role of illegal product supply and geographical location on the use of illegal cigarettes, in relation to that of legal cigarettes and RYO in the period of 2008-2014, involving substantial tax increases on manufactured legal cigarettes. During this period, tobacco taxes as well as the absolute and relative prices of legal cigarettes, as compared with illegal cigarettes, have changed. This paper compares the behaviour of smokers in response to these changes in five Uruguayan cities: Rivera, Salto, Durazno, Montevideo and Maldonado, where tax avoidance opportunities may vary. From a public health policy perspective, as Joossens and Raw highlighted, illegal cigarettes are a double threat to public health. First, smuggling makes cigarettes more affordable, and second, the tobacco industry uses smuggling as a political argument against tobacco tax increases. ${ }^{9}$ Switching from legal to illegal cigarettes reduces the impact of tobacco taxation aimed at reducing tobacco consumption which is a way of tax circumvention. Moreover, policies may be needed to help reduce trade in and consumption of illegal cigarettes.

\section{METHODS \\ Data}

Data were obtained from the ITC Uruguay Survey, a longitudinal survey designed to evaluate tobacco control policies. Sampling weights accounting for survey non-response were calculated for each of four waves of ITC surveys which have been conducted in five Uruguayan cities: Montevideo, Salto, Maldonado, Durazno

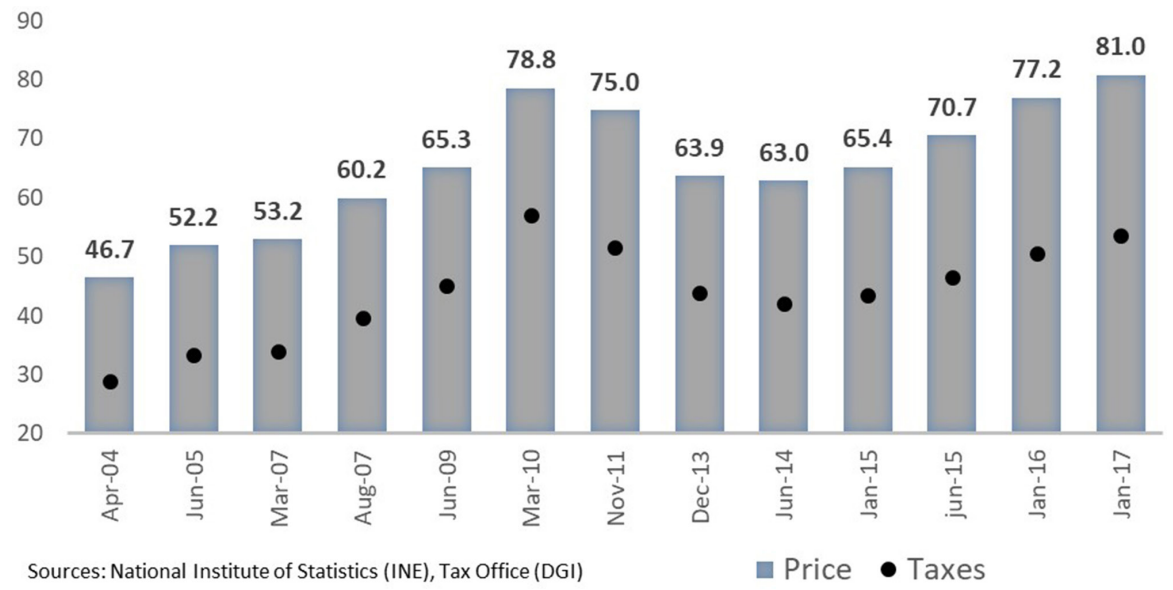

Figure 1 Real taxes and price per pack of cigarettes.

\footnotetext{
${ }^{\mathrm{v}}$ Cross-border shopping is not included in this analysis. Brands surveyed are mostly Paraguayan which enter illegally to Brazil or Argentina, and also enter illegally to Uruguay, that is, retail sales of these brands are contraband.
} 
and Rivera. The dates of these four waves were September 2008-February 2009, October 2010-January 2011, SeptemberDecember 2012 and September-October 2014. ${ }^{\mathrm{vi}}$

Data were collected through interviews with adult smokers aged 18 or older regarding their tobacco consumption, tobacco purchase information and socioeconomic, demographic and consumption characteristics. The price per cigarette or per pack/ pouch of tobacco was derived from the last purchase information. Detailed brand information and prices paid were used to identify the purchase/use of manufactured legal, manufactured illegal and RYO cigarettes. The average retention rate of the survey was approximately $70 \%$.

\section{VARIABLES}

Two dichotomous dependent variables were constructed to measure smokers' choice of illegal cigarettes over legal cigarettes or RYO. A proxy of illegal cigarette sales was constructed calculating per capita legal proceedings initiated for smuggling and custom fraud by city, using information from the judicial system (table 2) ${ }^{\text {vii }}$ This variable was calculated by dividing the number of legal proceedings initiated for smuggling and custom fraud (a rolling window averaging 3 years around the wave year) by city population. A significant proportion (more than 50\%) of cases were associated with cigarette smuggling.

Tax per pack of cigarettes for each survey wave was constructed as the key explanatory variable that affects smokers' choices between illegal and manufactured legal cigarettes. Similarly, taxes per pouch of RYO tobacco was constructed as a key variable that affects choices between illegal and RYO cigarettes.

City is a polytomous categorical variable that indicates in which city the smoker resides $($ Montevideo $=1$ referent, Durazno=2, Maldonado $=3$, Rivera $=4$, Salto $=5$ ); and city region is a dichotomous categorical variable that indicates whether the city is on the border (the smoker lives in Salto or Rivera $=1$ referent) or not (the smoker lives in Montevideo, Maldonado or Durazno=0).

\begin{tabular}{lllllll}
\hline $\begin{array}{l}\text { Table } 2 \\
\text { fraud, by city }\end{array}$ & Per capita legal proceedings for contraband and custom \\
\hline Year & Montevideo & Durazno & Maldonado & Salto & Rivera & $\begin{array}{l}\text { Cities } \\
\text { average }\end{array}$ \\
\hline 2008 & 11.6 & 3.5 & 4.5 & 26.3 & 37.4 & 11.4 \\
\hline 2010 & 10.7 & 1.6 & 2.9 & 18.3 & 31.9 & 11.0 \\
\hline 2012 & 10.9 & 1.5 & 5.5 & 16.1 & 22.1 & 11.2 \\
\hline 2014 & 6.4 & 3.1 & 4.1 & 13.7 & 33.9 & 9.9 \\
\hline
\end{tabular}

Source: Judiciary system statistical yearbooks 2007-2015.

\footnotetext{
${ }^{\text {vi The }} 2014$ wave sample size is 1428 , of which 1015 are from Montevideo, 99 from Rivera, 161 from Salto, 54 from Durazno and 109 from Maldonado. In the other waves, the simple size was about the same.

${ }^{\text {vii }}$ Statistical yearbooks of the judiciary system: http://poderjudicial.gub.uy/images/stories/anuario/si/anuario2007.pdf; http:// poderjudicial.gub.uy/images/stories/anuario_estadistico_2008. pdf; http://poderjudicial.gub.uy/images/stories/anuario/si/ anuario2009.pdf; http://poderjudicial.gub.uy/images/stories/ anuario/si/anuario2010.pdf; http://poderjudicial.gub.uy/images/ stories/anuario/Anuario/anuario_2011.pdf; http://poderjudicial.gub.uy/images/institucional/estadisticas/anuario_2012.pdf; http://poderjudicial.gub.uy/images/institucional/estadisticas/ Anuario_2013_Final.pdf; http://poderjudicial.gub.uy/images/ stories/anuario/Anuario/Anuario_2014.pdf; http://poderjudicial.gub.uy/images/institucional/estadisticas/Anuario_2015_ vFinal_05-08-16.pdf
}

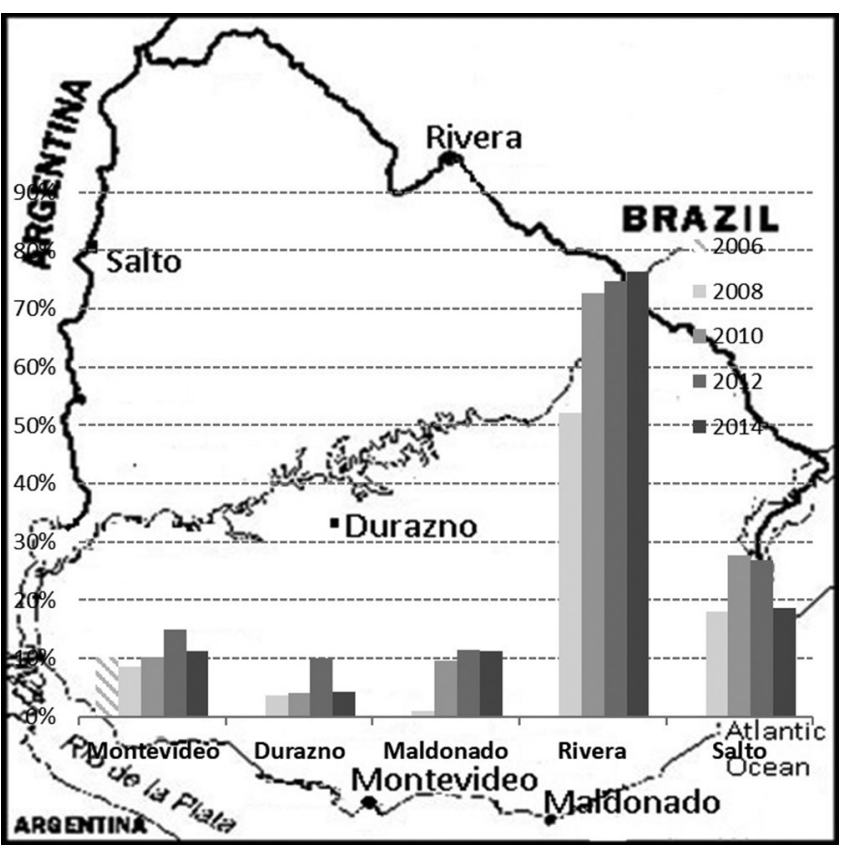

Figure 2 Smokers of illegal cigarettes (\%) — by cities. ITC, Tobacco Control Evaluation Project.

The socioeconomic and demographic characteristics include age (three categories: 18-35, referent; $36-64$ and $\geq 65$ years), highest education achieved (four categories: <middleschool, referent; middle school; high school and $>$ high school), household monthly income (three categories: \$U0-\$U12 500, referent; \$U12 500-\$U30 000; \$U>30 000) and gender (two categories: men $=0$, women $=1$ ). Consumption intensity is a continuous variable indicated as the average quantity of cigarettes smoked per day for each smoker.

\section{MODELS}

The first model (model 1 ) is to estimate the choice between legal and illegal cigarettes among smokers (identified using foreign brands and lower prices), in response to explanatory variables including cigarette taxes, geographical location (an indicator of illegal trade activity using city as a proxy of the supply of illegal products), other sociodemographic characteristics and cigarette consumption per day. As tax rates vary by survey wave, survey wave fixed effects were not used in the regressions.

The literature suggests that control effectiveness, corruption, informal distribution networks, organised crime and industry participation are factors that determine the sale of illegal cigarettes which play a significant role in the use of illegal tobacco products. ${ }^{8}{ }^{10-16}$ We used geographical locations as the proxy of these factors and hypothesised that smokers in border cities have more access to illegal cigarettes compared with smokers in other cities.

The analysis on the choice between illegal and legal cigarettes was conducted after dropping RYO smokers, and the comparison between illegal cigarettes and RYO was conducted after dropping smokers of legal cigarettes. As the ITC Uruguay survey is longitudinal, generalised estimating equations were used in order to account for intertemporal correlation. Logistic link, a binomial family and exchangeable correlation applied in estimating the model, is described in the following equation:

$\mathrm{Y}_{\text {it }}=\mathrm{b}_{0}+\mathrm{b}_{1}$ tax pack/pouch $+\mathrm{b}_{2}$ city $+\mathrm{b}_{3}$ city_border $+\mathrm{b}_{4}$ offer_ille$\mathrm{gal}+\mathrm{b}_{5} \mathrm{Xit}$

Tax pack/pouch is tax per pack/pouch in pesos (real value) for each survey wave. $\mathrm{X}_{\mathrm{it}}$ is a vector of individual-level sociodemographic 


\section{Research paper}

Table 3 Binomial models estimated by generalised estimating equations-ORs

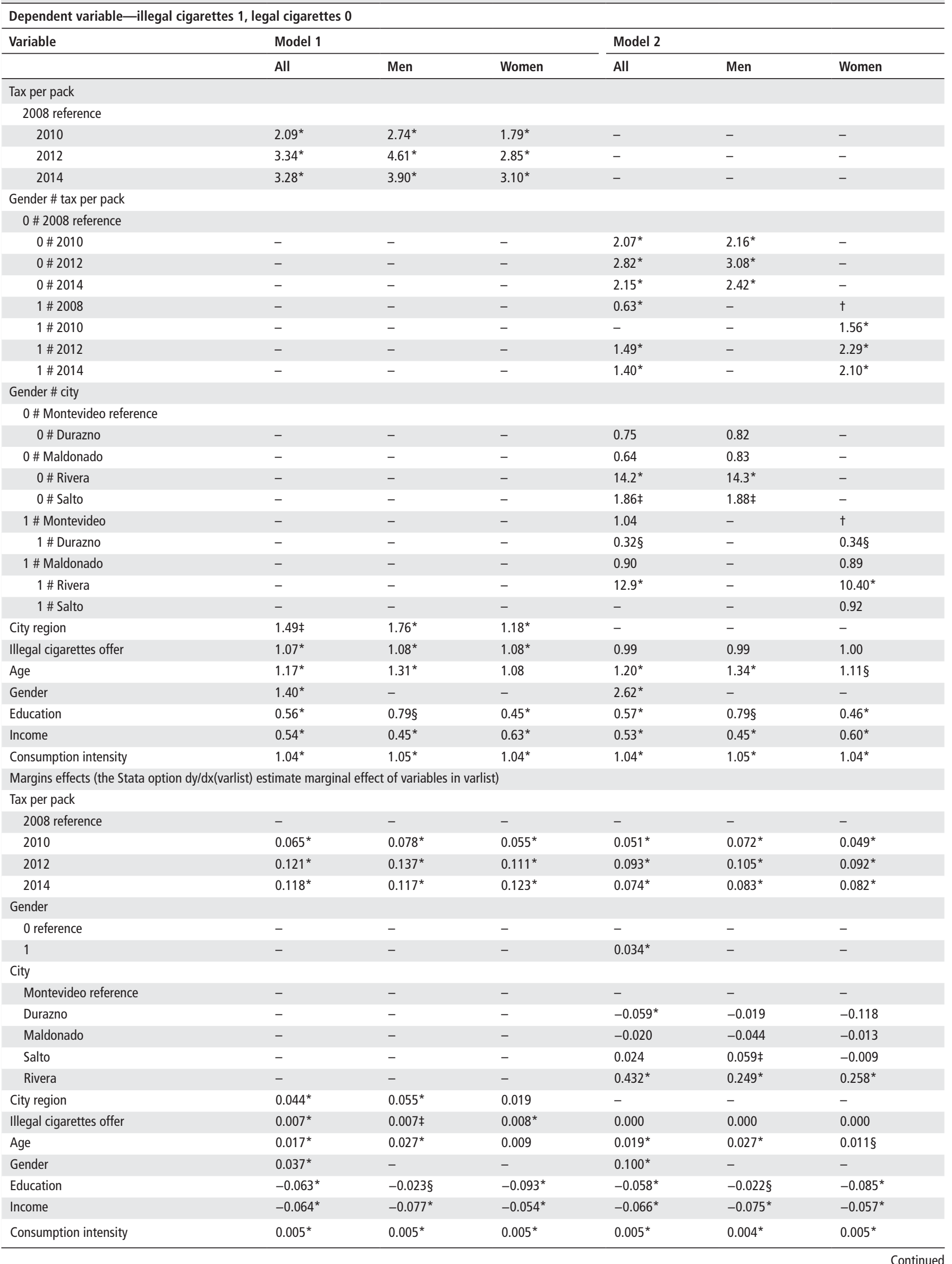


Table 3 Continued

\begin{tabular}{|c|c|c|c|c|c|c|}
\hline \multirow[t]{2}{*}{ Variable } & \multicolumn{3}{|c|}{ Model 1} & \multicolumn{3}{|c|}{ Model 2} \\
\hline & All & Men & Women & All & Men & Women \\
\hline Observations & 3804 & 1613 & 2191 & 3804 & 1613 & 2191 \\
\hline $\begin{array}{l}\text { Significant at } \\
* 1 \% \text {. } \\
\text { †In model } 2 \text { u } \\
\neq 5 \% \text {. } \\
\S 10 \% \text {. }\end{array}$ & tev & & & & & \\
\hline
\end{tabular}

characteristics and consumption intensity. We also conducted stratified analyses (model 2) using a full interaction model that includes the interactions of gender with the rest of the variables.

\section{RESULTS}

Successive surveys revealed that the percentage of smokers who chose illegal cigarettes in Rivera and Salto were higher than those in the three cities that were not close to the border (Durazno, Maldonado and Montevideo). The changes in percentages varied by cities over the survey waves of 2008, 2010, 2012 and 2014 (figure 2).

Our analytical results also showed that the consumer choice between illegal and legal cigarettes was significantly different between border cities and others. In addition, gender, educational level, income, age and the amount of cigarettes consumed per day were significant factors in explaining which populations were those who chose cheaper illegal cigarettes during the study period when taxes and prices changed.

Model 1 estimate shows that the probability of choosing illegal cigarettes has increased in higher tax years (2010, 2012 and 2014) compared with the year of lower tax (2008) (table 3). This may indicate that increases in price raise the likelihood that a smoker chooses illegal over legal cigarettes. Both genders are more likely to choose illegal cigarettes than legal cigarettes in 2010, 2012 and 2014 compared with 2008 (model 2) and women compared with men (model 1, all). The probability of choosing illegal cigarettes in relation to legal cigarettes is higher in border cities than in non-border cities, and this probability is higher in Rivera and Salto and lower in Durazno compared with Montevideo for men (model 2).

The probability of choosing illegal cigarettes for men and women in Rivera and for men in Salto is higher than for men in Montevideo. In Rivera, the OR is between 13 and 14 times greater than for men in Montevideo (model 2). The probability of choosing illegal cigarettes for women in Durazno is lower than for women and men in Montevideo (model 2, women and all).

The probability of choosing illegal cigarettes over legal cigarettes is greater for women and increases with age and with greater intensity of consumption, while decreasing with higher educational level and higher income.

In table 4, it is showed that smokers are more likely to choose illegal cigarettes than RYO in years of higher RYO taxes (2010, 2012, 2014) with respect to 2008 (lower taxes) (model 1), but this result is explained by behaviour of smokers in border cities (city region variable in model 1) as well as men in Rivera compared with men in Montevideo (model 2). Conversely, the same probability for smokers in Durazno and Maldonado is lower than for men in Montevideo (model 2). The increase of RYO tax does not affect the behaviour of men and women in choosing illegal cigarettes over RYO for all years and for all cities in the same way. In some years or cities, the ORs are not statistically significant, that is, higher taxes do not change the probability of choice between RYO and illegal cigarettes.

The probability that men choose illegal cigarettes over RYO in 2010 and 2014 (higher taxes) is not statistically different from men in 2008 (lower taxes), but is higher in 2012. The probability of women choosing illegal cigarettes over RYO in 2010 (higher taxes) is lower than for women in 2008 (lower taxes, model 2, women), and it is not statistically different in 2012 and 2014 compared with 2008 for women; hence, women are least likely to switch to illegal cigarettes when RYO taxes increase.

The OR of choosing illegal cigarettes over RYO is almost 6 and 12 times higher for female smokers as compared with male smokers in models 1 and 2, respectively. The probability of choosing illegal cigarettes over RYO is higher if the smoker is older and smokes more intensively.

All models' estimates suggest that educated people prefer manufactured cigarettes (legal or illegal cigarettes) to RYO which is consistent with the descriptive statistics that men belonging to lower socioeconomic strata mostly smoke RYO.

\section{Discussion and conclusion}

Price differentials between legal and illegal cigarettes are important in Uruguay, where illegal cigarettes have been about 60\% cheaper than legal cigarettes between 2006 and 2014. Significant changes in the taxation of tobacco products following the implementation of the FCTC of WHO in Uruguay generated a case to evaluate their impact on smokers' choices between legal and illegal cigarettes.

Although price gap is an incentive for the consumption of illegal cigarettes, whether and to what extent the consumption of illegal products increases merit further investigation. For example, it is possible that the supply of illegal products increases when the profits of wholesale and retail distributors increase as a result of a greater price gap between legal and illegal cigarettes. This potential supply change could have affected the consumption of illegal cigarettes.

When taxes and prices increase, behaviour of smokers is different across time and cities about switching tobacco products. In the case of the five Uruguayan cities surveyed, in Montevideo and Durazno, illegal cigarette consumption did not increase, however it increased in the border cities of Rivera and Salto, although not permanently in the last city.

On one hand, the results of this study suggest that higher taxes on manufactured legal and RYO cigarettes increase the probability that some smokers could switch to illegal counterparts, for example, people living in border cities. On the other hand, the same probability decreases in cases such as people who live in Durazno, Maldonado or Montevideo (illegal cigarettes vs RYO), or it is not significant, like women who live in Maldonado or Salto (illegal cigarettes vs legal cigarettes, model 2). 
Table 4 Binomial models estimated by generalised estimating equations-ORs

\begin{tabular}{|c|c|c|c|c|c|c|}
\hline \multicolumn{7}{|c|}{ Dependent variable-illegal cigarettes 1, roll-your-own 0} \\
\hline \multirow[t]{2}{*}{ Variable } & \multicolumn{3}{|l|}{ Model 1} & \multicolumn{3}{|l|}{ Model 2} \\
\hline & All & Men & Women & All & Men & Women \\
\hline \multicolumn{7}{|l|}{ Tax per pouch } \\
\hline \multicolumn{7}{|l|}{2008 reference } \\
\hline 2010 & 1.03 & $1.28^{*}$ & $0.80 \dagger$ & - & - & - \\
\hline 2012 & $1.40 \dagger$ & $1.82 \dagger$ & 1.01 & - & - & - \\
\hline \multicolumn{7}{|l|}{0 \# 2008 reference } \\
\hline 0 \# 2010 & - & - & - & 1.06 & 1.06 & - \\
\hline 0 \# 2012 & - & - & - & $1.30 \ddagger$ & $1.36 \ddagger$ & - \\
\hline 0 \# 2014 & - & - & - & 1.03 & 1.07 & - \\
\hline 1 \# 2008 & - & - & - & 1.19 & - & $\S$ \\
\hline \multicolumn{7}{|l|}{ Gender \# city } \\
\hline \multicolumn{7}{|c|}{0 \# Montevideo reference } \\
\hline 0 \# Durazno & - & - & - & $0.30 \ddagger$ & $0.35 \ddagger$ & - \\
\hline 0 \# Maldonado & - & - & - & $0.49^{*}$ & $0.49^{*}$ & - \\
\hline 0 \# Rivera & - & - & - & $8.40 \dagger$ & $8,43+$ & - \\
\hline 0 \# Salto & - & - & - & 0.77 & 0.83 & - \\
\hline 1 \# Montevideo & - & - & - & $0.39^{*}$ & - & $\S$ \\
\hline 1 \# Durazno & - & - & - & $0.17 \ddagger$ & - & 0.40 \\
\hline 1 \# Maldonado & - & - & - & 0.47 & - & 1.18 \\
\hline 1 \# Rivera & - & - & - & 1.44 & - & $2.84 \dagger$ \\
\hline 1 \# Salto & - & - & - & - & - & 2.10 \\
\hline \multicolumn{7}{|c|}{ Margins effects (The Stata option (dy/dx(varlist) estimate marginal effect of variables varlist) } \\
\hline \multicolumn{7}{|l|}{ Tax per pack } \\
\hline 2008 reference & - & - & - & - & - & - \\
\hline 2010 & 0.007 & 0.048 & $-0.041 \dagger$ & -0.010 & 0.0135 & $-0.036 \ddagger$ \\
\hline 2012 & 0.068 & $0.123+$ & 0.001 & $0.040 \ddagger$ & $0.058 \ddagger$ & 0.008 \\
\hline 2014 & $0.048+$ & $0.079 \ddagger$ & 0.022 & 0.016 & 0.012 & 0.028 \\
\hline \multicolumn{7}{|l|}{ Gender } \\
\hline 0 reference & - & - & - & - & - & - \\
\hline 1 & - & - & - & $0.366 t$ & - & - \\
\hline \multicolumn{7}{|l|}{ City } \\
\hline Montevideo reference & - & - & - & - & - & - \\
\hline Durazno & - & - & - & $-0.193 \dagger$ & $-0.198^{*}$ & -0.162 \\
\hline Maldonado & - & - & - & -0.057 & $-0.134^{*}$ & 0.029 \\
\hline Salto & - & - & - & 0.041 & 0.036 & 0.130 \\
\hline Rivera & - & - & - & $0.355 t$ & $0.405 t$ & $0.183+$ \\
\hline City region & $0.127 \dagger$ & 0.037 & $0.187 \dagger$ & - & - & - \\
\hline Illegal cigarettes offer & $0.006+$ & $0.012 \dagger$ & -0.001 & - & - & - \\
\hline Age & $0.026 t$ & 0.000 & $0.079 \dagger$ & $0.032 \dagger$ & 0.007 & $0.079 \dagger$ \\
\hline Gender & $0.358 t$ & - & - & $0.463 t$ & - & - \\
\hline Education & $0.058 \dagger$ & $0.115 \dagger$ & -0.032 & $0.060 \dagger$ & $0.116 t$ & -0.024 \\
\hline Income & 0.005 & -0.004 & 0.009 & 0.003 & -0.002 & 0.011 \\
\hline
\end{tabular}


Table 4 Continued

\begin{tabular}{|c|c|c|c|c|c|c|}
\hline \multicolumn{7}{|c|}{ Dependent variable-illegal cigarettes 1 , roll-your-own 0} \\
\hline \multirow[t]{2}{*}{ Variable } & \multicolumn{3}{|c|}{ Model 1} & \multicolumn{3}{|c|}{ Model 2} \\
\hline & All & Men & Women & All & Men & Women \\
\hline Observations & 1289 & 731 & 558 & 1289 & 731 & 558 \\
\hline $\begin{array}{l}\text { Significant at } \\
* 10 \% \text {. } \\
+1 \% \text {. } \\
\neq 5 \% \text {. }\end{array}$ & & & & & & \\
\hline
\end{tabular}

Several hypotheses may explain our finding that smokers in border cities are more likely to switch to cheaper illegal cigarettes than smokers elsewhere. There may be a greater supply of illegal cigarettes in border cities due to higher permeability to illegal products from neighbouring countries. This larger amount of supply may result from the geographical location of the border cities $^{10} 11^{17-19}$; difficulties for the authorities to impose effective controls on border cities due to multiple channels of illegal cigarette entry and the existence of well-established distribution networks that smugglers use for cigarettes and other products. In the cities of Montevideo, Maldonado and Durazno, the geographical location and the government's ability to control imports may be associated with less opportunity for smuggling and fewer distribution channels of illegal products, compared with border cities.

This study provides some evidence that the geographical location of cities, distribution networks and controls effectiveness may play a significant role in the change of the use of illegal cigarettes and its extent.

In border cities, controls are less effective due to the possibilities of avoiding them and the existence of informal distribution networks which leads to a greater supply of illegal products including cigarettes. The supply of illegal cigarettes has an important role in the choice of smokers because it increases the nearby availability of illegal cigarettes.

A tobacco tax policy aimed at reducing tobacco prevalence is necessary, together with specific policies to reduce the sale of illegal cigarettes. Improving the effectiveness of controls on the borders and in populous cites could help to decrease the odds of smokers switching from manufactured legal and RYO cigarettes to illegal cigarettes by reducing their supply.

The models estimated show that use of illegal cigarettes is determined by variables associated with the supply of illegal cigarettes which is related to geographical location of cities, tobacco control effectiveness, and social and personal characteristics of smokers. Countries that increase tobacco taxes will not necessarily see an increase in consumption of illegal cigarettes if the supply of illegal cigarettes is limited or reduced. This pattern is seen in areas far away from the borders in Uruguay, since they receive less supply of illegal cigarettes compared with border cities.

Gender is also a factor, as the widespread use of RYO among men renders it a potential substitute for legal and illegal cigarettes for men. This also implies that illegal cigarettes may become a closer substitute for women as they do not generally use RYO, although illegal cigarettes are more expensive than RYO.

Cigarette affordability, as measured using price in relation to income, could also play an important role in determining the choice (demand) of smokers between legal and illegal cigarettes. Presumably, those who have lower incomes may be more likely to choose cheaper illegal cigarettes as legal cigarettes become less affordable for them.
In summary, when a country increases tobacco taxes, border cities require specific policy interventions aimed at mitigating larger incentives for the illicit trade of cigarettes such as tightened custom controls, cooperation between bordering countries regarding customs and other related areas, and using the influence of local governments and civil society to counteract the sale of illegal tobacco by formal retail, using the media to communicate strong messages against illegal tobacco sales.

The ratification and effective implementation of the Protocol to Eliminate Illicit Trade in Tobacco Products of WHO (PEITTP) is a comprehensive policy to fight against the illicit trade of tobacco products which can also be used to enact a wide set of measures. Uruguay needs to implement the PEITTP, adapting it to its own situation, considering that along border cities illegal cigarette use and trade is significant, and taking into account that the big market is Montevideo and the metropolitan area.

Mercosur countries are responsible for cigarette contraband because tobacco leaves are grown in their territories. Moreover, Brazil and Argentina have the political influence among Mercosur countries to pressure Paraguay to change this situation, however they have their own responsibility. The cigarette contraband problem requires a political solution, and a quid pro quo negotiation among Mercosur countries with Paraguay is key to the real solution to this issue in the long run. This notwithstanding, implementing the Protocol can help in the meantime if it is appropriately implemented, considering the situation of the countries in the region.

Tax increases diminishing price differentials should be a goal from a policy perspective because they reduce the incentives for illegal trade of tobacco products which requires policy coordination among finance ministries in the region. A minimum specific excise tax, and to some extent, tax harmonisation in the region could also help to avoid tax arbitrage, reducing price gaps and aligning incentives to reduce

What this paper adds

- This paper provides evidence that supply and consumption of illegal cigarettes in Uruguay differ by geographical locations.

- The existence of distribution networks and weak controls in cities near the Uruguayan borders play a role in access to illegal cigarettes.

- Policies intended to reduce the supply of illegal cigarettes such as ratification and effective implementation of the Protocol to Eliminate Illicit Trade of Tobacco Products of WHO, and to some extent, taxation harmonisation among countries in the region, are needed to ensure that tobacco tax policies have the desired impact on public health. 
the sale of illegal cigarettes and increase the effectiveness of tax increases in reducing smoking.

Correction notice This article has been corrected since it was published Online First. Additional details of funding have been added.

Acknowledgements The authors would like to thank Anne C K Quah for her input in the earlier drafts of this paper and Hye Myung and Rich Gallagher for editing the paper. The authors would also like to thank the ITC Uruguay Principal Investigators, Eduardo Bianco and Marcelo Boado, for their leadership and acknowledge their interviewers for their role in data collection. Moreover, we are grateful to three anonymous reviewers who have helped to improve the manuscript. All errors are our own.

Collaborators Anne Chiew Kin Quah.

Contributors DC, CS, FJC and GTF planned the work as described in the article. DC and CS conducted the analysis, wrote the draft and reported the work after discussion with other authors. DC is responsible for the overall content as guarantor.

Funding The ITC Uruguay Project was supported by grants P50 CA111236 (Roswell Park Transdisciplinary Tobacco Use Research Center) and P01 CA138389 from the US National Cancer Institute, International Development Research Centre (IDRC), and Canadian Institutes of Health Research (115016, 118096 and FDN 148477). Additional support was provided to Geoffrey T Fong from a Senior Investigator Award from the Ontario Institute for Cancer Research and a Prevention Scientist Award from the Canadian Cancer Society Research Institute. Additional support in preparing this paper was provided to University of Waterloo by the Canadian Institutes of Health Research (FDN-148477).

Competing interests None declared.

Patient consent Not required.

Ethics approval Office of Research Ethics, University of Waterloo, Canada and International Research Board, Universidad de la Republica, Uruguay.

Provenance and peer review Not commissioned; externally peer reviewed.

\section{REFERENCES}

1 Wilkins N, Yurekli A, Hu T. Economics of Tobacco Toolkit, Tool 3: economic analysis of tobaccco demand. Washington DC.: World Bank, 2013.

2 Shang C, Chaloupka FJ, Zahra N, et al. The distribution of cigarette prices under different tax structures: findings from the International Tobacco Control Policy Evaluation (ITC) Project. Tob Control 2014;23(Suppl 1):i23-9.
3 Shang C, Chaloupka FJ, Fong GT, et al. The association between tax structure and cigarette price variability: findings from the ITC Project. Tob Control 2015;24:iiï8-93.

4 Curti D, Shang C, Ridgeway W, et al. The use of legal, illegal and roll-your-own cigarettes to increasing tobacco excise taxes and comprehensive tobacco control policies: findings from the ITC Uruguay Survey. Tob Control 2015;24:iii17-iii24.

5 Ramos A. Illegal trade in tobacco in Mercosur countries. Trends in Organized Crime 2009;12:267-306.

6 Joossens L, Raw M. How can cigarette smuggling be reduced? BMJ 2000;321:947-50.

7 Joossens L, Raw M. Smuggling and cross border shopping of tobacco in Europe. BMJ 1995;310:1393-7.

8 Joossens L, Raw M. Cigarette smuggling in Europe: who really benefits? Tob Control 1998:7:66-71.

9 Iglesias RM, Szklo AS, Souza MC, et al. Estimating the size of illicit tobacco consumption in Brazil: findings from the global adult tobacco survey. Tob Control 2017;26:53-9.

10 Von Lampe K. et al Explaining the emergence of the cigarette black market in Germany. In: Petrus C, Lampe K, Dijck M, Newell JL, . eds. The organised crime economy, managing crime markets in Europe: Wolf Legal Publishers (WLP) 2005:209-29.

11 Beare ME. Organized corporate criminality: Tobacco smuggling between Canada and the US. Crime. Law \& Social Change 2002;3:225-43.

12 Beare ME. Organized Corporate Criminality: Corporate Complicity in Tobacco Smuggling. Beare ME, ed. Critical Reflections on Transnational Organized Crime. Money Laundering and Corruption. Toronto: University of Toronto Press, 2003:183-206.

13 Joossens L, Chaloupka FJ, Merriman D, et al. Issues in the smuggling of tobacco products. In: Jha P, Chaloupka F, eds. Tobacco Control in Developing Countries. Oxford: Oxford University Press, 2000:393-406.

14 Merriman D, Yurekli A, Chaloupka FJ. How big is the worldwide cigarette-smuggling problem? In: Jha P, Chaloupka F, eds. Tobacco Control in Developing Countries. Oxford: Oxford University Press, 2000:365-92.

15 Legresley E, Lee K, Muggli ME, et al. British American Tobacco and the insidious impact of illicit trade in cigarettes across Africa. Tob Control 2008;17:339-46.

16 Titeca K, Joossens L, Raw M. Blood cigarettes: cigarette smuggling and war economies in central and eastern Africa. Tob Control 2011;20:226-32.

17 Schwartz R, Johnson T. Problems, policies and politics: a comparative case study of contraband tobacco from the 1990s to the present in the Canadian context. J Public Health Policy 2010;31:342-54.

18 Lakhdar CB. Quantitative and qualitative estimates of cross-border tobacco shopping and tobacco smuggling in France. Tob Control 2008;17:12-16.

19 Ceccato V, Haining R. Crime in border regions: The Scandinavian case of Öresund, 1998-2001. Ann Assoc Am Geogr 2004;94:807-26. 